\title{
Hubert Der Kirchenaufbruch Feichtlbouer hielt nicht an \\ 50 wechselvolle Jahre des Verbands katholischer Publizisten Österreichs
}

Es war die Zeit, als Zehntausende junger Menschen Fahnen schwingend durch die Straßen unserer Städte zogen und „Wir sind bereit, rufen es weit: Gott ist der Herr auch unserer Zeit! " in Sonne und Regen schmetterten. Schon bald nach dem Ende von Diktatur und Weltkrieg, nicht erst zum Vatikanischen Konzil, herrschte Aufbruchstimmung in Gesellschaft, Staat und Kirche (worunter damals ein jeder die seine verstand). Schlussstrich und Neubeginn, Gedanken- und Redefreiheit, Demokratie und Religionsbekenntnis waren angesagt. Was katholisch war, neigte zum Outing: Frauen und Männer, Junge und Alte, Fußball spielende Kapläne und Leitartikel drechselnde Schreiberlinge.

Bekenner brauchen Gemeinschaft, suchen Gleichgesinnte, kultivieren Schulterschluss und frohe Solidarität. So wuchsen die Organisationsformen der Katholischen Jugend, der Männer- und Frauenbewegung, der wieder erweckten Studentenverbindungen und der neu gegründeten $\mathrm{Ka}$ tholischen Arbeiterbewegung. Kein Wunder, dass 1947 in Graz auch führende Personen des katholischen Pressewesens eine Arbeitsgemeinschaft katholischer Publizisten (AKP) grïndeten, die - ein später nicht mehr erreichter Sammelbegriff - Journalisten, Herausgeber, Verleger, Publizistikwissenschafter, schreibende Theologen und gläubige Schriftsteller unter einem gemeinsamen Dach vereinen sollte. Forderungen nach höherer Papierzuteilung durch die Besatzungsmächte, phantasievolle Planungen für eine katholische Tageszeitung reichten für ein erstes Solidaritätserlebnis - für mehr leider nicht. An der Frage, ob die neue Vereinigung unabhängig oder im Verband der Katholischen Aktion (KA) agieren sollte, zerbrach die erste Initiative. In der Folge entstand eine Arbeitsgemeinschaft katholischer Journalisten im KA-Gefuige und eine autonome Gemeinschaft katholischer Zeitungs- und Zeitschriftenverlage.

Der erste Nachkriegs-Katholikentag sorgte 1952 für eine Neuzündung. Die Bischöfe hatten ein Pressekomitee unter Vorsitz Otto Schulmeisters eingerichtet, der in der Folge Jahrzehnte lang das Gesicht der bürgerlich-liberalen, jetzt auch kirchenfreundlichen Tageszeitung „Die Presse" und des katholischen Journalismus dariiber hinaus prägen sollte. Eine Studientagung im Wallfahrtsort Mariazell sammelte Katholikentagsthemen und setzte dabei deutliche Medienakzente: Die Kirche sollte in der neuen Kommunikationswelt heimisch werden. Ein „Mariazeller Manifest" durchtrennte die historische Achse von Thron und Altar (seit 
1918 Christenpartei und Pfarrhof): „Die Kirche ist ohne Rücksicht auf Parteibekenntnis für alle da! " war die neue Losung.

Das war schon deutlich die Handschrift des jungen Bischof-Koadjutors Franz König, noch genauer: die Handschrift von dessen Handschriftführer Richard Barta, Chefredakteur der Kathpress. Und es war eine medienwirksame Handschrift! Person und Wirken des späteren Wiener Erzbischofs und Kardinals Franz König haben zur Medienpräsenz der katholischen Kirche bis heute entscheidend beigetragen. Vaticanum II verlieh dieser Präsenz nicht selten Titelseitenwert. Kein Wunder, dass da auch der Verband katholischer Publizisten Österreichs (VKPÖ) blühte und gedieh, der 1957 als Dachorganisation für die Arbeitsgemeinschaft katholischer Journalisten und die katholische Verlegergemeinschaft geschaffen worden war. Ein Aufruf Königs am Vorabend des Konzils wurde rasch zum Vademecum der Medienleute: „Wenn Sie etwas zu sagen haben, warten Sie nicht auf den Bischof, nicht auf eine Nachricht aus Rom! Mahnen Sie, wo Sie glauben, mahnen zu müssen, drängen Sie, wo Sie glauben, drängen zu müssen! “

\section{Die Dialog-Ära des Franz König}

Sie mahnten und drängten mit Freuden, die Kirche fuhr gut damit, bis heute, und Vergleichbares ist seither keinem Bischofsmund mehr entwichen. Es wäre freilich falsch zu behaupten, die gesamte österreichische Bischofskonferenz hätte sich dieser Parole freudig angeschlossen. Kaum ein Bischof hat je zur Gänze alle Vorbehalte gegen fürwitzige Medienleute und ihr Tun abschütteln können. Aber das Beispiel Königs, der seit Ende 1952 auch „Pressebischof" war, riss doch die meisten mit, und das neu erwachte Medieninteresse an Kirche und Kirchlichem gefiel. So ist zu erklären, dass es in Österreich damals auch gelang, katholische Publizisten beiderlei Geschlechts nicht nur aus kircheneigenen, sondern auch aus säkularen Medien für den Verband und den neuen Kirchenkurs zu gewinnen: Öffnung zu anderen christlichen Kirchen hin, zu Zweiflern und Fernstehenden, zu neugierigen Sozialdemokraten, modernen Wissenschaftern und selbst zu erklärten Religionsgegnern - die „Paulus-Gesellschaft" suchte und versuchte den Dialog auch mit marxistischen Philosophen aus kommunistischen Nachbarländern.

Jahre später sollte der aus Deutschland beruflich nach Österreich übersiedelte Kommunikationswissenschafter Michael Schmolke konstatieren: „Anders als in Deutschland, wo man etwa in der Publizistischen Kommission des Zentralkomitees der Deutschen Katholiken zwar auch einige Asse, aber eben doch die typische katholische Auswahl mit libe- 
ralen Einsprengseln traf, fand man im (österreichischen) Verband eine breite Auswahl des ernst zu nehmenden österreichischen Journalismus. " Jahrestagungen mit anspruchsvollen Themen aus Religion, Politik, Kultur und Medien fanden regen Zuspruch, auf internationalen Veranstaltungen stellten die Österreicher überproportional starke Kontingente und ergriffen so manche Initiative.

An der schon 1927 erfolgten Gründung der Katholischen Weltunion der Presse (Union catholique internationale de la presse, UCIP) hatte schon der katholische Publizist Friedrich Funder aus Wien mitgewirkt. Damals ein militanter Christlichsozialer (einschließlich des damit verbundenen "wirtschaftlichen" Antisemitismus), war der durch KZ-Jahre geläuterte katholische Publizist nach 1945 ein wortgewaltiger Anwalt von partei- und konfessionsübergreifender Katholizität geworden und zusammen mit Generaldirektor Karl Maria Stepan vom katholischen Pressverein Styria maßgeblich daran beteiligt, dass schon 1957 ein UCIP-Weltkongress in Wien stattfand. 1977 folgte ein zweiter UCIPKongress in Wien, 1995 ein dritter auf österreichischem Boden in Graz.

\section{Intensive Mitarbeit in der UCIP}

Bald schon nach 1945 waren Österreicher in Leitungsgremien der UCIP aktiv, und katholische Verlage in Österreich griffen dem Weltverband mehrfach auch finanziell kräftig unter die Arme. (Die UCIP-Finanzen stehen bis zum heutigen Tag auf wackeligen Beinen.) Zwei Perioden lang (1980-1986) war Stepan-Nachfolger Hanns Sassmann gewählter Präsident der UCIP, für eine Periode (1996-1999) stellte Österreich den Vorsitzenden der UCIP-Region Europa. Daneben beteiligten sich katholische Publizisten und Publizistinnen aus Österreich auch frühzeitig an der Gemeinschaftssuche im deutschsprachigen Raum; 1954 fand das erste deutsch-österreichische Treffen in Salzburg statt.

In den sechziger Jahren wurden Gemeinschaftsveranstaltungen deutscher, österreichischer und schweizerischer Medienleute („Drei-LänderTreffen" sagte man seit 1969) eine feste Institution, zu denen früh schon auch deutschsprachige Kollegen aus Südtirol, Luxemburg und vereinzelt auch Liechtenstein stießen. Am Drei-Länder-Treffen in Dürnstein im Herzland der Weinregion Wachau 1981 mit Kardinal König und Otto B. Roegele nahmen 47 Personen aus Österreich, 34 aus der Bundesrepublik Deutschland, 14 aus der Schweiz und Einzelgäste aus Italien, Ungarn und Jugoslawien teil. Neben dem Tagungsthema (in Dürnstein „Was machen wir aus der Kirche?") gab es immer auch Begegnungen mit dem kulturhistorischen Ambiente (nach dem 3. Kreuzzug saß der englische 
König Richard Löwenherz in der Burg hoch über Dürnstein als Geisel des Babenberger Herzogs ein). Dazu kam viel Zeit für die Pflege persönlicher Beziehungen, die in vielen Fällen zu nachhaltigen Freundschaften geworden sind.

Regelmäßige Kontakte mit dem Bayerischen Presseclub (der erste gleichfalls 1954) bildeten gewissermaßen ein kräftiges Unterholz im deutschsprachigen katholischen Medienwald. Die enge persönliche Verbindung zwischen den beiden Hauptpersonen Hanns Sassmann in Graz und KNA-Landeschef Norbert Stahl in München spielten dabei eine wichtige Rolle. Publizistenverband und Presseclub brachten 1991 in Brixen und noch einmal in St. Georgen am kärntnerischen Längssee zwei Erklärungen zum Thema Kirche und Medien zustande, die die kirchlichen Mediendokumente "Inter mirifica" und "Communio et Progressio" in ihren Hauptaussagen über öffentliche Meinung auch in der Kirche, Transparenz, Freiheit, Offenheit und Selbstkritik noch einmal zuspitzten. Im Nachhinein fragt man sich: wozu? Sind doch schon die unzugespitzten Grundsätze nie wirklich umgesetzt worden.

1990 fand das letzte Drei-Länder-Treffen im Bildungshaus Puchberg bei Wels statt, das ganz im Zeichen der „Wende" stand. 1994 kam es noch einmal zu einer Ausweitung österreichisch-bayerischer Aktivitäten durch Gründung einer Arbeitsgemeinschaft katholischer Publizisten aus den Alpen-Adria-Ländern (ADA), die das Fallen von Grenzen dokumentieren sollte. Das Experiment versandete nach wenigen Jahren - vielleicht, weil schon lange vor der Wende viel Fahnenschwenken und Bruderschafttrinken praktiziert worden war und jetzt in allen Ländern harte Arbeit angesagt war. Aber nun endlich muss auf das "Fahnenschwenken davor" noch eingegangen werden.

\section{Ostmitteleuropa als Programm}

Ein Schwergewicht grenzübergreifender österreichischer Aktivitäten innerhalb und außerhalb der UCIP bildete von Anbeginn das Bemühen um Kontaktnahme mit Kollegen und Kolleginnen im kommunistischen Einflussbereich Europas. So wie sich die katholischen Publizisten Deutschlands aus guten Gründen vor allem um eine Aussöhnung mit Frankreich bemüht und dabei Bleibendes geleistet haben, schien es den Österreichern, sie hätten eine vielfach belastete Vergangenheit im Verhältnis zu den Völkern der ehemaligen Habsburger-Monarchie aufzuarbeiten. So früh wie möglich wurde versucht, Verbindungen über den Eisernen Vorhang herzustellen, Hauptanliegen der kirchlich orientierten Verleger und Journalisten $\mathrm{zu}$ ergründen und geistig wie finanziell $\mathrm{zu}$ helfen, wo dies 
möglich war. "Das ging so weit, dass man dabei weder die Devisenvorschriften noch diplomatische Gepflogenheiten immer einhalten konnte", konstatiert im Rückblick der langjährige Hauptexponent des Katholischen Pressvereins der Diözese Linz - und der "Osthilfe“ -, Hubert Lehner.

Schon 1959 begannen mit einer Einladung an katholische polnische Journalisten nach Österreich die Beziehungen zu Polen, die sich im Ver. lauf der Jahre besonders eng gestalten sollten. Eine zentrale Rolle spielte dabei Wladyslaw Bartoszewski, Mitarbeiter der Krakauer Wochenzeit. schrift "Tygodnik Powszechny", früherer Nazi- und Kommunisten. häftling, der nach der Wende polnischer Botschafter in Wien, zweimal kurz auch polnischer Außenminister war und zur Versöhnung mit Deutschen und Juden Entscheidendes beigetragen hat. Auf österreichischer Seite war ihm von Anbeginn „Furche"-Chefredakteur Kurt Skalnik ein wichtiger Partner. Nicht selten tauchte auch ein Krakauer Erzbischof zu Gesprächen über die Finanzierung von Druckmaschinen oder Fachleuteausbildungen bei Prälat Franz Willinger im Katholischen Pressverein St. Pölten auf, der sich später als Papst Johannes Paul II. nannte. Viele Besuchsreisen in beide Richtungen schufen Kooperationen, Freundschaften und Geldkanäle.

1966 begannen intensive Kontakte mit Kroatien, 1968 mit der damaligen Tschechoslowakei, 1970 mit Slowenien und 1971 mit Ungarn. Hubert Lehner erinnert sich eines Vorfalls beim UCIP-Kongress in Luxemburg 1971, als ein tschechischer Geistlicher teilnehmen wollte und auf tiefes Misstrauen der UCIP-Granden stieß, weil er keine Bischofsempfehlung mitbrachte. Kurz entschlossen „adoptierten“ die Österreicher den Unbekannten, der sich des Vertrauens als würdig erwies und von Lehner beim 50-Jahre-Jubiläum in Wien als nunmehr alter Freund vorgeführt werden konnte. Zuletzt kamen auch katholische Medienleute aus dem Baltikum und selbst aus Russland in den Genuss des Lehnerschen Sponsoring-Programms, in dessen Verlauf viele hunderte Bibeln und Gebetbücher in den Kofferräumen österreichischer Diplomaten den Eisernen Vorhang gequert hatten und der Aufbau ganzer Verlags- und Druckereieinrichtungen in Ländern Mittelosteuropas ermöglicht worden war. Lehner dankte namens des österreichischen Publizistenverbandes auch internationalen Hilfswerken in Deutschland, den USA und anderen Ländern sowie privaten Unternehmern für Vertrauen und Geld.

\section{Zerfall von Verbandsstrukturen}

50 Jahre Verband katholischer Publizisten Österreichs - eine Erfolgsstory? Ja und nein. Was im Sog kirchlicher Aufbrüche getan werden konnte, 
ist getan worden und hat Spuren hinterlassen. Aber das tat auch die weitere Entwicklung in Kirche und Gesellschaft. Die auch als persönliche Kränkung von Kardinal König aufzufassenden Bischofsernennungen in der Nach-König-Ära bremsten Schwung und Begeisterung. Wahrheitspflicht gebietet die Feststellung, das auch schon, als König noch der Bischofskonferenz vorsaß, manche Eingaben des Publizistenverbandes unbeachtet blieben. Das episkopale Ignorieren eines mühsam erarbeiteten Pressekonzepts für Tages-, Wochen- und Kirchenzeitungen, Kinder-, Jugend-, Fach- und Ordensschriften, die Nachrichtenagentur Kathpress, diözesane Pressestellen, Bücher, elektronische Medien und Weiterbildungseinrichtungen hat besonders geschmerzt. Die zeitweise Personenidentität der Vorstände des Publizistenverbands, der Pressekommission der Bischofskonferenz und der Katholischen Medienakademie (KMA) wurde auf Wunsch des Verbandes in den neunziger Jahren wieder beendet - kaum je war Rat gefragt gewesen.

Die KMA hat unter neuer Leitung bis zum heutigen Tag fruchtbar gearbeitet - ihre Absolventen sind in Österreichs Medien unterschiedslos gefragt. Andere Stellen des kirchlichen Medienwesens wurden von der Bischofskonferenz aufgelöst oder in zentralistische Strukturen eingegliedert. Der Chefredakteur von Kathpress ist heute gleichzeitig Presseamtschef der Erzdiözese Wien, der Chefredakteur der Salzburger Kirchenzeitung war von 1995 bis 31. Juli 2007 auch Pressesprecher der Erzdiözese Salzburg: prinzipiell unvereinbare Positionen! Persönliche Glaubwürdigkeit mag den Unfug fürs Erste erträglich machen, aber Parallelfälle in Deutschland (Köln u.a.) legen den Verdacht systematischer Gängelungspolitik nahe. Kardinal Christoph Schönborn, persönlich sympathisch, weltmännisch im Auftreten, versöhnlich in der Tonart, hat der katholischen Kirche in Österreich wieder Frieden gebracht - aber es ist in Vielem der Scheinfriede einer Kirchenlandschaft, über die eine große Decke gebreitet worden ist. Weil keinem Reformwunsch mehr amtskirchlich widersprochen (aber auch keiner erfüllt) wird, entdecken die Medien kein berichtenswertes Kriegsgetümmel mehr, und das Reformgemurmel wird überhört.

Seit Jahren gibt es keine großen Verbandstagungen mehr. Die monatlichen jours fixes mit interessanten Gesprächspartnern aus vielen Bereichen des öffentlichen Lebens, die der unvergessene Anton Fellner eingeführt hat, sind trotz unterschiedlicher Besucherzahlen immer noch Dauerbrenner im Programm. Aber der generelle Individualisierungstrend mehrt Zweifel an der weiteren Sinnhaftigkeit katholisch oder auch nur christlich punzierter Verbandsstrukturen. Symptomatisch dafür ist ja auch die Tatsache, dass sich die Gemeinschaft katholischer Zeitungsund Zeitschriftenverlage vor einigen Jahren sang- und klanglos aufgelöst 
hat. Mangels Aufgabenstellung, wie man hörte. Klar: Für unternehmensübergreifende Medienveranstaltungen hat man längst kein Geld mehr, auch nicht für die Teilnahme hauseigener Journalisten an solchen, und die einst als geistig-geistliche Welteroberungswerkzeuge gegründeten katholischen Pressvereine sind zu Einzelfirmen geschrumpft oder schaufeln durch Anteilsverkäufe Einmal-Geld in Diözesanbudgets. „Professionalisierung vom vormaligen Sendungsbewusstsein hin zum ökonomisch Effizienten", nannte das einer der köstlichsten Formulierer der Verlegerbranche in der Festschrift, die zum 50-Jahre-Jubiläum des VKPÖ am 12. April 2007 im Erzbischöflichen Palais in Wien erschienen ist und auf dessen Inhalte sich auch dieser kursorische Rückblick stützt.

Ebenfalls kann man darin aber auch von der Ende 2005 gewählten ersten weiblichen Verbandsvorsitzendes lesen, dass sie im 50. Bestandjahr mehr als drei Dutzend neue Kolleginnen und Kollegen werben konnte. "Wann," fragt sie, „wenn nicht jetzt soll es diesen Verband geben?" Arbeitsplatzsorgen, Bemühen um Qualität trotz Konkurrenzdnuck, Vorbildsuche - „das alles braucht Kraft, Bestärkung und Ermutigung“. Diese quirlige Gabriele Neuwirth haben männliche Verbandshaudegen am Anfang gewaltig unterschätzt. Warten wir einmal die weitere Entwicklung $\mathrm{ab}$. 